\title{
Cycloaddition reactions of cyclophanes
}

\author{
Soichi Misumi \\ The Institute of Scientific and Industrial Research, Osaka \\ University, Ibaraki, Osaka 567, Japan

\begin{abstract}
Unusual thermal and photochemical cycloaddition reactions of the aromatic rings in some cyclophanes are described. For example, the benzene in paracyclo $(9,10)$ anthracenophane functions as a dienophile in intramolecular DielsAlder reaction and tetracyanoethylene reacts easily with a triple-layered cyclophadiyne even at room temperature to give a 1:1 cycloadduct, suggesting a concerted process of three isolated $\pi$-systems. The formation of cage compounds by photoinduced cycloaddition and their reverse, thermal ring opening reactions are observed with syn[2.2] (1,4)anthracenophane and dihetera quadruple-1ayered cyclophanes. A quantitative photodimerization of $(9,10)$ anthracenophadiyne and photoinduced bridge migration of multilayered metaparacyclophanes are discussed.
\end{abstract}

\section{INTRODUCTION}

The most striking characteristic of [2.2]para- and metacyclophanes is anomalous behavior in electrophilic substitution of the two benzene rings, which is caused on the transannular $\pi$-electron interactions among the stacked henzenes to function just as one $\pi$-electron system. In addition, severe strain of benzene nuclei in such stacking systems, $i . e$. bending and twisting, brings about them some extent of thermodynamical destabilization or reduced aromatic character. As a result, the "superdienophile" 4-pheny1-1,2,4-triazoline-3,5dione, for example, reacts with [2.2] paracyclophane to give a $1: 2$ cycloadduct 1 ( $99 \%$ yie1d) after 6 days at room temperature, although it does not add to benzene at room temperature even after several weeks (ref. 1). Also, tetracyanoethylene does not add to benzene and even to [2.2]paracyclophane at $100^{\circ} \mathrm{C}$ for $165 \mathrm{hr}$, whereas it gives readily a $1: 1$ adduct $\underline{2}$ (100\% yield) of [2.2.2.2] $(1,2,4,5)$ cyclophane at $20^{\circ} \mathrm{C}(\operatorname{ref} .2)$.

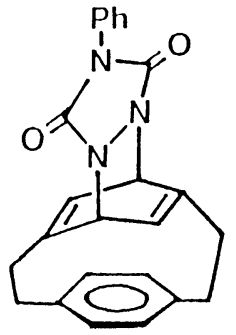

1

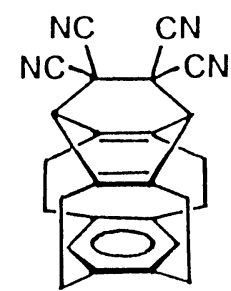

2

As model compounds to study the transannular m-electron interactions in stacked aromatic systems, we have synthesized various types of cyclophanes which contain some extended aromatics (ref. 3), diacetylene bond (ref. 4), and multistacked benzene systems(ref. 5). During the study on physical and chemical properties of these cyclophanes, we found that they often show remarkable non-catalytic reactions, i.e. thermal and photochemical cycloadditions, due to their severe strain and transannular m-electron interactions. 


\section{THERMAL CYCLOADDITION}

\section{Anthracenophanes}

In anticipation of stronger transannular m-electron interactions in the cyclophanes of condensed aromatics than that in [2.2]paracyclophane, we prepared a series of anthracenophanes, i.e. benzene-anthracene, naphthaleneanthracene, and anthracene-anthracene systems (ref. 6). Some isomeric anthracenophanes are expected due to the difference in stacking mode of two aromatic rings. A longer wavelength shift in electronic spectrum of [2.2]paracyclo$(9,10)$ anthracenophane 4 was ascribed to stronger interaction between the two $\pi$-systems, compared to that of the corresponding $(1,4)$ isomer 3 ( $r e f .6)$. Synthesis of isomeric triple-layered anthracenophanes, $\underline{5}$ and $\underline{6}$, was undertaken by employing the Hofmann elimination method of the corresponding ammonium bases. The isomer 5 was obtained in low yield, but in the case of anthracenophane $\underline{6}\left(\mathrm{R}=\mathrm{CH}_{3}\right)$ an isomeric cage compound $\underline{7}\left(\mathrm{R}=\mathrm{CH}_{3}\right)$ was isolated from the reaction mixture in $1.5 \%$ yield( $7: R=H 8.7 \%$ yield)(ref. 7$)$. The structures of 7 were determined by PMR and X-ray analysis.
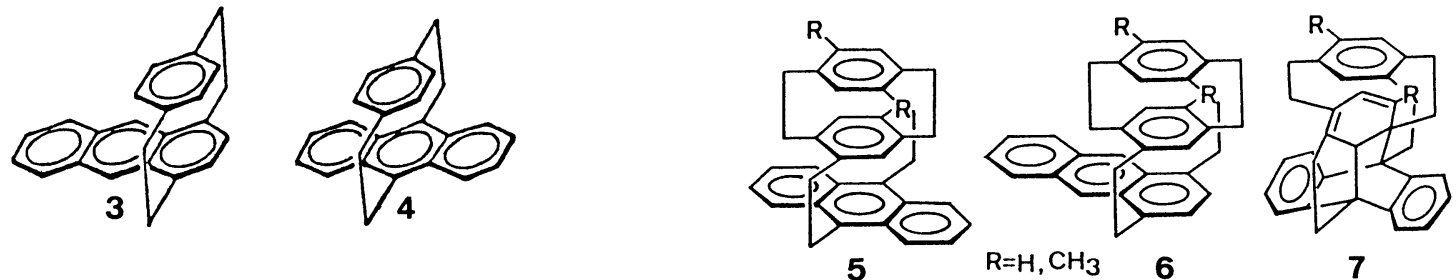

The formation of $\underline{7}$ is illustrated by intramolecular Diels-Alder addition of the inner benzene ring as a dienophile to the 9,10-positions of the anthracene ring. This unusual cycloaddition under ordinary reaction conditions can be accounted for by close fixing of the anthracene ring against the inner benzene ring with two ethylene bridges, and by severe molecular strain in the intermediate 6 , as same as in X-ray molecular structures of triple-(ref. 8) and quadruple-1ayered cyclophanes (ref. 9), in which both inner benzene rings are bent into twisted form. In other words, strain releasing is responsible for the unusual addition reaction. The thermal instability of anthracenophane 4 , which polymerizes gradually even in crystalline state at room temperature, is also attributable to the same reason.

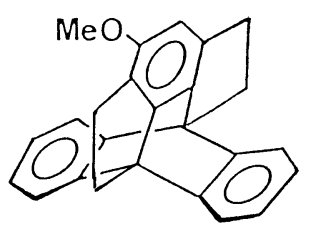

8

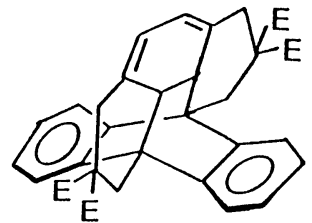

9

$\left(\mathrm{E}=\mathrm{CO}_{2} \mathrm{Et}\right)$

The formation of a bridged triptycene 8 is interpreted by a reaction sequence of Diels-Alder addition and following elimination of a methanol molecule (ref. 10). Although an attempt to regenerate the labile intermediate 6 by retro Diels-Alder reaction of $\underline{7}$ was unsuccessful, a cycloadduct having propylene bridges $\underline{9}$ showed a reverśsible reaction to the original anthracenophane(ref.11).

\section{Cyclophadiynes}

In the course of a study on charge transfer complexes, $\underline{10}$ and $\underline{11}$, of [n]paracyclophadiyne or [m.n]paracyclophadiyne with tetracyanoethylene (ref. 12),

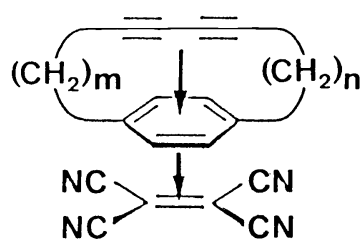

10

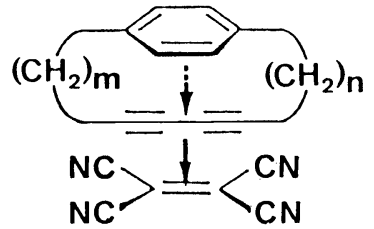

11 
Tab1e 1. Reaction conditions and yields of TCNE to [m.n]paracyclophadiynes 12 .

\begin{tabular}{|l|c|c|c|c|}
\hline$[\mathrm{m} . \mathrm{n}]$ & $\mathrm{R}$ & Reac.temp. $\left({ }^{\circ} \mathrm{C}\right)$ & Reac.time & yield(\%) \\
\hline$[2.3]$ & $\mathrm{H}$ & & ---- & -- \\
{$[2.4]$} & $\mathrm{H}$ & 140 & $30 \mathrm{~min}$ & 76 \\
{$[3.3]$} & $\mathrm{H}$ & 140 & $30 \mathrm{~min}$ & 73 \\
{$[3.3]$} & $\mathrm{CH}_{3}$ & 75 & $19 \mathrm{hr}$ & 88 \\
{$[3.4]$} & $\mathrm{H}^{3}$ & 140 & $70 \mathrm{~min}$ & 34 \\
{$[4.4]$} & $\mathrm{H}$ & 140 & & 0 \\
\hline
\end{tabular}

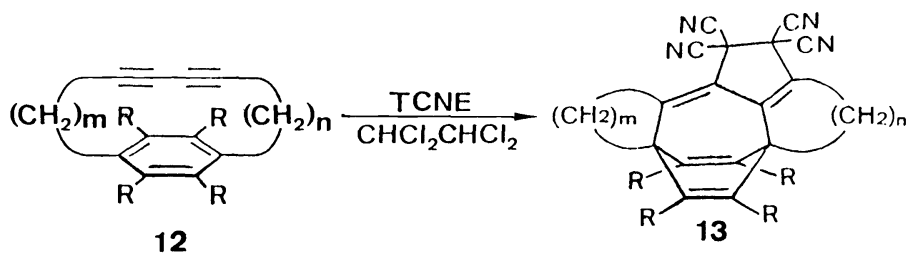

we found that a novel multicycloaddition took place among three isolated $\pi$-systems (ref. 13). Immediately after addition of TCNE to [3.3]paracyclophadiyne 12 in tetrachloroethane, the solution changes to blue color for a short time, suggesting the formation of CT complex, and it becomes quickly colorless. The structure of colorless product $13(\mathrm{R}=\mathrm{H}, \mathrm{m}, \mathrm{n}=3)$, isolated from the solution, is clearly confirmed by spectral analyses, that is, IR, UV, PMR and 13 C-NMR, which indicate the reaction to proceed with the disappearance of diacetylene bond and the inner benzene ring. In particular, NMR spectra show evidently the formation of unsymetric structure 13 via 1,3 -mode reaction of three kinds of cycloaddition modes as shown in Fig. 1 .
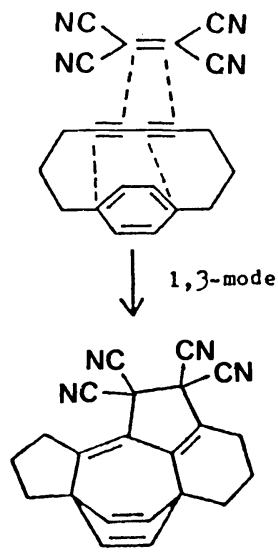
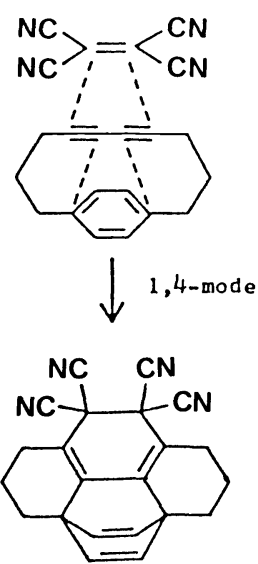
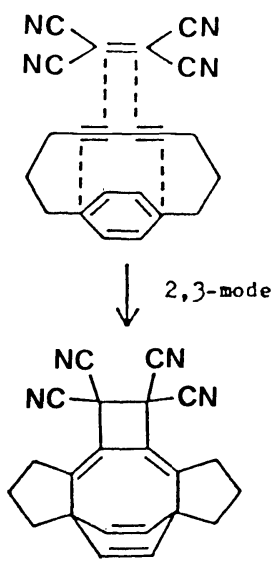

Fig. 1. Cycloaddition modes of TCNE to [3.3]paracyclophadiyne.

Such a cycloaddition reaction is also observed with higher homolog $12(R=H, m=3$, $\mathrm{n}=4$ ) to give lower yield of $\underline{13}$, but no formation of cycloadduct with $12(R=H$, $\mathrm{m}, \mathrm{n} \geqslant 4$ ) (Table 1). On the other hand, tetramethyl derivative $\underline{12}\left(\mathrm{R}=\mathrm{CH}_{3}, \frac{12}{\mathrm{~m}}, \mathrm{n}=3\right)$ of [3.3]paracyclophadiyne undergoes the cycloaddition under milder conditions and in higher yield, compared to those of the parent [3.3]- and an isomer [2.4] paracyclophadiyne $\underline{12}(\mathrm{R}=\mathrm{H}, \mathrm{m}=4, \mathrm{n}=2)$ having the same length of the bridge.

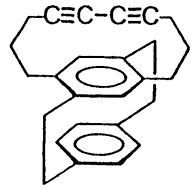

14

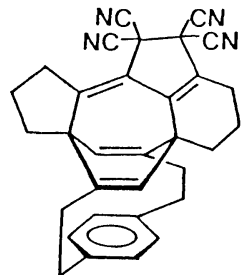

15 


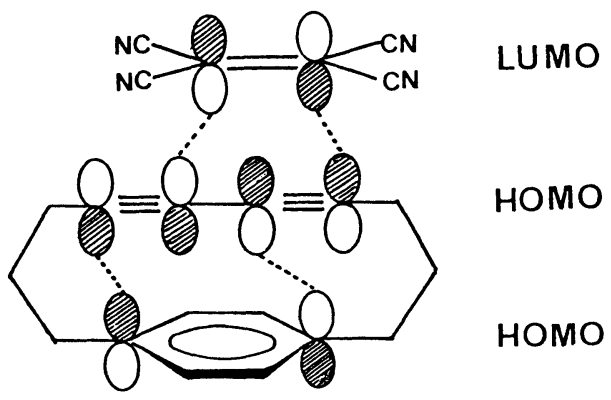

Fig. 2. The three $\pi$-system interaction orbital set for multicycloaddition of [3.3] paracyclophadiyne with TCNE.

On the other hand, more severely strained cyclophadiyne 14 (ref. 4) reacts readily with TCNE even at room temperature to give a cyc1oadduct 15 (ref. 13). On the basis of several examples above-stated, the easiness of this intriguing multicycloaddition is concluded to be depend strongly upon magnitudes of both the strain and the electron donating ability of the benzene ring faced to diacetylene group.

A mechanism of this multicycloaddition was first thought as an example of a thermally allowed $[\pi 4 s+\pi 2 a+\pi 2 s+\pi 2 a] p e r i c y c l i c$ process, provided that the cycloaddition proceeds in a concerted manner. Later the reactions were interpreted on the basis of molecular orbital theory, that is, in terms of three $\pi$-systems interaction among the HOMO of the benzene ring, the HOMO of the conjugated diacetylene group, and the LUMO of TCNE as shown in Fig. 2 (ref. 14). There the theory claimed that highly electron-deficient TCNE allows the HOMO-HOMO interaction, which is prohibited normally in thermal reaction, between the diyne group and the benzene ring for stabilization and bond formation.
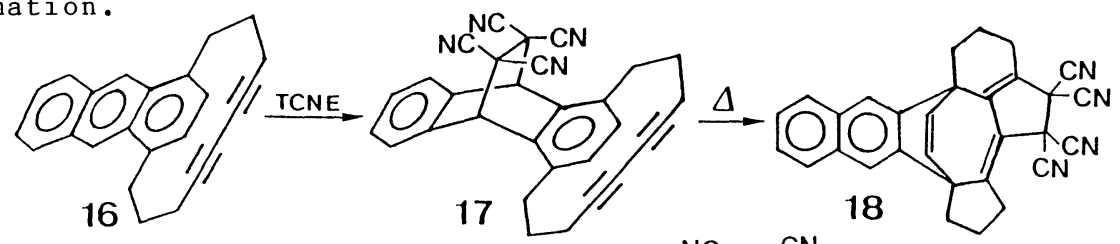

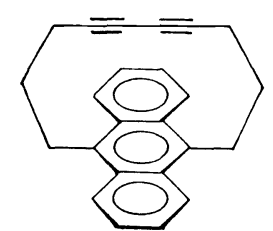

19

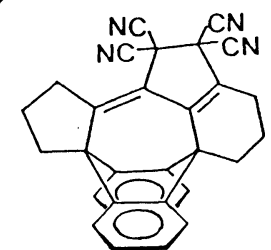

20

In the case of $[10](1,4)$ anthracenopha-4,6-diyne $\underline{16}$, TCNE is added exclusively to $9,10-p o s i t i o n s$ of the anthracene ring to give quantitative yield of an adduct 17, because of ready CT complex formation and the following Diels-Alder addition reaction. When the adduct 17 in tetrachloroethane is refluxed, an isomeric $1: 1$ adduct $\underline{18}$ is given in $38 \%$ yield, probably through a retro DielsAlder process followed by the above-stated multicycloaddition mechanism among three $\pi$-systems. Similarly, isomeric 9,10-anthracenophadiyne 19 yields a cycloadduct $\underline{20}$ with TCNE.

\section{PHOTOCHEMICAL CYCLOADDITION}

Two types of photoinduced cycloadditions on irradiation of anti[2.2] $(1,4)-$ naphthalenophane 21 are wel1-known as a typical example of condensed aromatics phane to give cycloadduct $\underline{22}$ by two consecutive $[\pi 2+\pi 2]$ reaction and cycloadduct $\underline{23}$ by $[\pi 4+\pi 4]$ reaction (ref. 15).

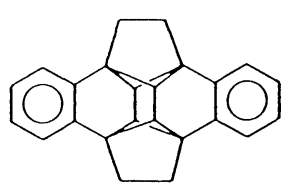

22

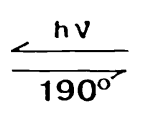

$90^{\circ}$<smiles>c1ccc2c3c(ccc2c1)CCc1c-3ccc2c1CC2</smiles>

21

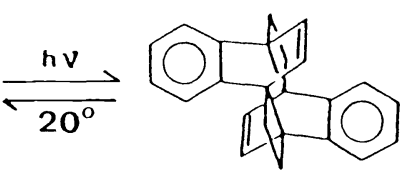

23 


\section{Anthracenophanes}

The first photoinduced cycloaddition of anthracenophane was observed on irradiation of $[2.2](9,10)$ anthracenophane $\underline{24}$ to give a strained cage compound 25 which showed a reverse, thermal reaction to 24 , that is, indicating the photochromism just as with naphthalenophane 21 (ref. 16).

In order to study the effect of sandwich type m-electron interaction on excimer fluorescence, photodimerization, and esr spectra of anthracene, we have synthesized a series of cyclophanes incorporating anthracene which has a lower ionization potential than either naphthalene and benzene. Using Hofmann elimination method of the corresponding quaternary ammonium bases, three isomeric [2.2] anthracenophanes $\underline{26}-\underline{28}$ are obtained (ref. 6).
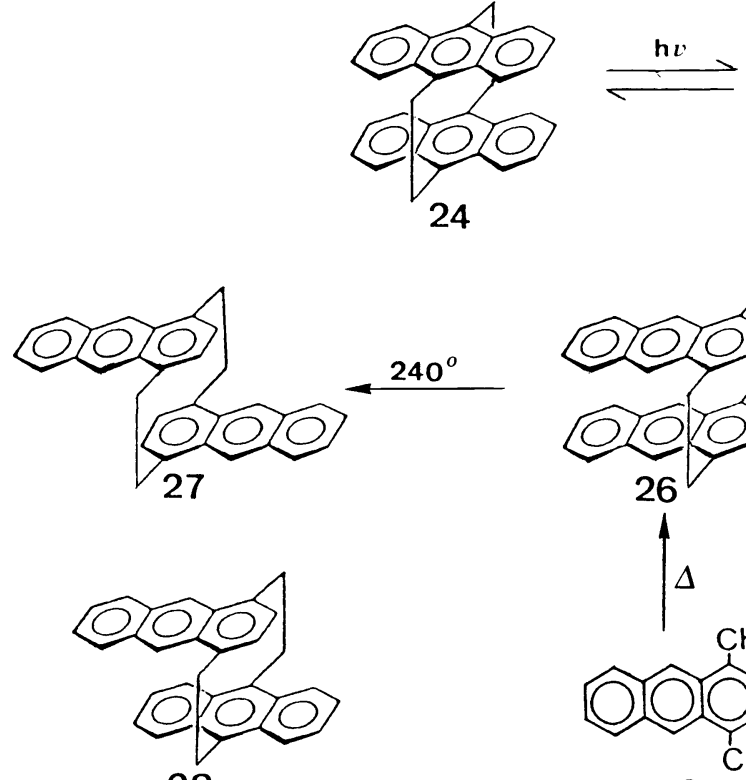

28

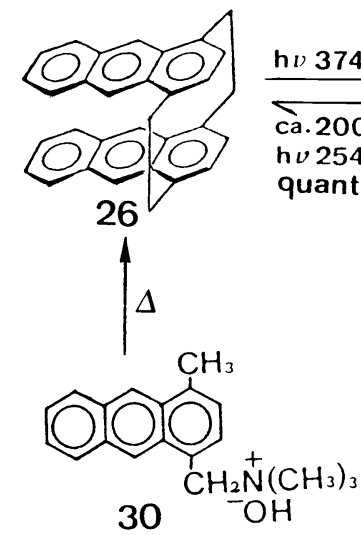

30

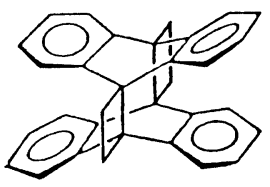

25

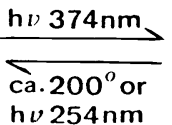

quant.

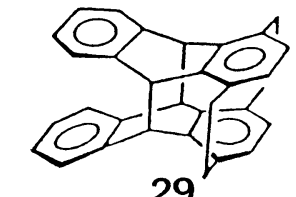

29

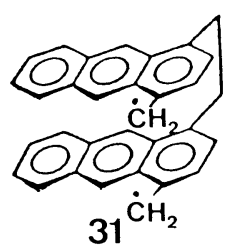

Irradiating with sunlight or monochromatic 1 ight at $374 \mathrm{~nm}$ in benzene, yellow syn[2.2] $(1,4)$ anthracenophane $\underline{26}$ gives an isomeric, colorless cage compound $\underline{29}$ in quantitative yield. The reverse, thermal reaction of cage compound $\underline{29}$ in solid state is performed to give quantitative yield of 26 under conditions at 198-199 ${ }^{\circ} \mathrm{C}$ for $6 \mathrm{hr}$ in nitrogen atmosphere. On the other hand, when the pyrolysis is carried out in solution at ca.220 ${ }^{\circ} \mathrm{C}$, a mixture of anti-isomer 27 and syn-isomer 26 of anthracenophane is given with a molar ratio of $21: 19$ as the reaction prolongs. This difference in pyrolytic reactions in both solid and solution can be understood as follows. In solution an anthracęne 3 biradical species 31,wich is formed by homolytic cleavage of an sp $-\mathrm{sp}^{3} \mathrm{sing}$ le bond in ethylene bridges, can rotate with biradical pairing and regenerate the single bond to give thermodynamically stable anti-isomer 27 . In solid state, on the other hand, the aromatic ring is unable to rotate due to less degrees of freedom for molecular motion and therefore more hindered syn-isomer 26 is selectively afforded. A photochemical interconversion between 26 and $\underline{29}$ is observed on irradiation of their THF solutions. Thus, when a THF solution of 29 is exposed to monochromatic 1 ight at $254 \mathrm{~nm}$ for $10 \mathrm{~min}$, the formation of 26 is observed in the electronic spectrum of resulting solution, and conversely, $\underline{26}$ to $\underline{29}$ by irradiation of $374 \mathrm{~nm} 1$ ight.

The molecular structure of 26 , in which the two anthracene rings are fixed in nearly parallel with relatively short distances, is shown in Fig. 3 (ref. 17). The figure demonstrates considerable overlapping among the two anthracene $2 \mathrm{Pz}$ electrons and thereby ready formation of covalent bonds between two pairs of $\mathrm{C}_{9}$ and $\mathrm{C}_{10}$ anthracene carbons. 


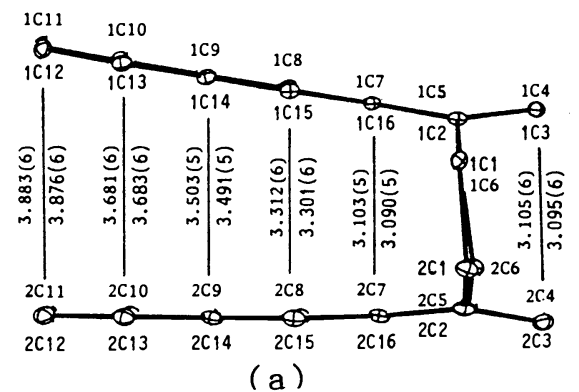

(a)

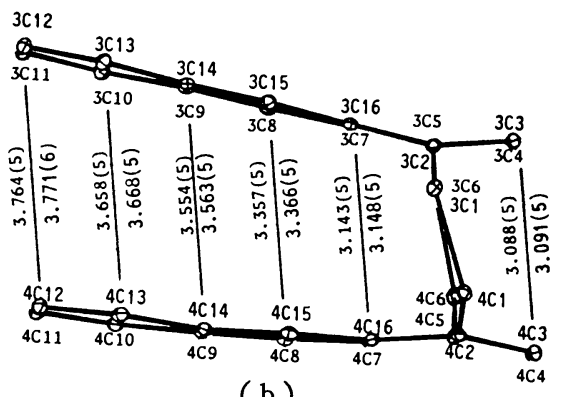

(b)

Fig. 3. A side view of syn-anthracenophane molecules, (a): A molecule, (b) : B molecule.

As an application of anthracene photochromism above-stated, a macrocyclic anthracenophane 32 was synthesized by the Williamson synthesis with polyethyleneglycol ditosylate (ref. 18). In other words, the incorporation of 1,2dianthrylethane groupin a macrocyclic polyether ring offers a possibility of selective metalion complexation-transportation by means of photo-controlled and reversible modification of the macrocyclic cavity. The selective complexation of alkali metal ion with $\underline{32}(n=1,2,3)$ was confirmed by measuring iondependent half-1ives of thermal, dark reaction of 33 to 32 , compared to that of ion-free case.

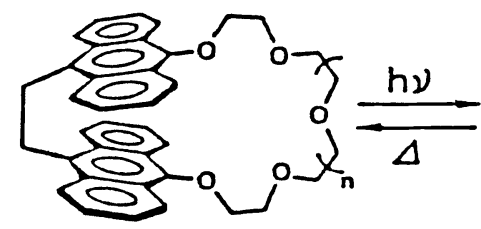

32

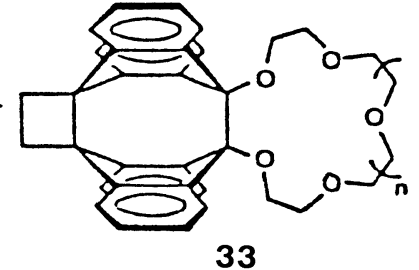

33

\section{Anthracenophadiyne}

Besides being susceptible to multicycloaddition with TCNE as described before, anthracenophadiyne 19 gives, on exposure of a benzene solution to sunlight for 10 min, an interesting dimer $\mathrm{C}_{48} \mathrm{H}$, in quantitative yield (ref. 3,19 ). When 19 in large excess of furan or 48 yclopentadiene 36 ( $\mathrm{X}=0$ or $\mathrm{CH}_{2}$ ) is exposed to sunlight for $30 \mathrm{~min}$, a $1: 1$ adduct, $\mathrm{C}_{28} \mathrm{H}_{24} \mathrm{O}$ or $\mathrm{C}_{29} \mathrm{H}_{26}$, is obtained in quantitative yield. The structure of the photodimer $\underline{39} 16^{\circ}$ determined by PMR and decoupled ${ }^{3}$ C-NMR spectra, lack of C $\equiv C$ stretching band in IR, and similarity with [4]radialene in UV spectra. The structures of two $1: 1$ cycloadducts are similarly assigned to $\underline{30}\left(\mathrm{X}=0, \mathrm{CH}_{2}\right)$ by spectral analyses.

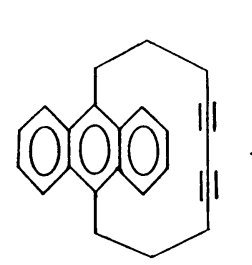

19

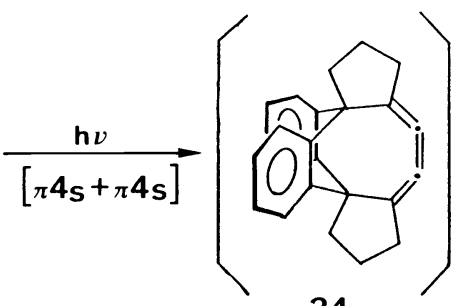

34

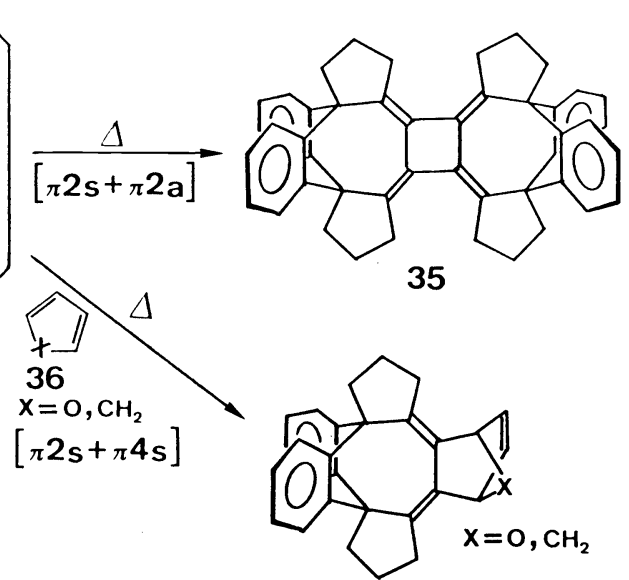

37

Extensive study on mechanism of the photoinduced dimerization elucidated an extremely strained butatriene derivative $\underline{34}$ to be the most likely intermediate on the basis of the following results: 1) al1 the reactions are independent of the concentration of reactant $\underline{19}$ with no detectable side reaction, 2) the reaction rate is proportional to the light intensity used for irradiation, 3) the intermediate $\underline{34}$ is trapped by repeated cycles of freezing-softening-UV 
irradiation process with a matrix of $\underline{19}$ in glycerol-ethanol (1:1) at $77 \mathrm{~K}$ and it reverts quantitatively to the reactant 19 by irradiation with shorter wavelength light, 4) the intermediate $\underline{34}$ in the same matrix gives the dimer $\underline{35}$ by warming up to room temperature in the dark, and 5) the absorption spectrum of $\underline{35}$ is similar to that of tetra-tert-butylbutatriene except its absorption intensity. Taking into account that this photodimerization is not affected by the presence of oxygen or radical scavenger, the reaction is explained to proceed by a two-step mechanism involving photochemically allowed [ $\pi 4 \mathrm{~s}+\pi 4 \mathrm{~s}$ ] and the following [ $\pi 2 \mathrm{~s}+\pi 2 \mathrm{a}]$ thermal processes. Thereby the formation of the two cycloadducts 37 is interpreted also by a two-step mechanism of Diels-Alder cycloaddition of the first-formed intermediate 34 with furan or cyclopentadiene.

\section{Multilayered cyclophanes}

A series of triple- and quadruple-layered [2.2]metaparacyclophanes is synthesized by a combination of general methods, since they have been of great interest on physical properties as intermediates between multilayered paraand metacyclophanes.
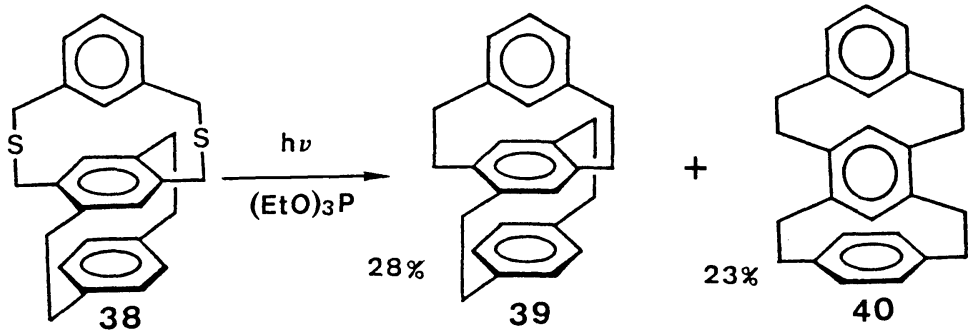

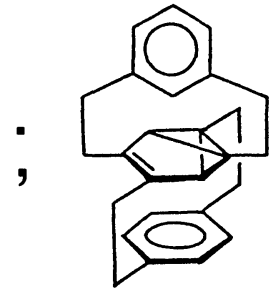

41

Photoinduced desulfurization of dithia[3.3]metaparacyclophanes is convenient as a general method for small scale preparation of [2.2]metaparacyclophanes (ref. 21). In the photodesulfurization of dithia triple-layered metaparacyclophane 38 in degassed triethyl phosphite with a high pressure mercury lamp, an unexpected isomeric triple-layered metaparacyclophane 40 is obtained in $23 \%$ yield together with about equal amounts of the desired metaparacyclophane 39 (ref. 22). For this case is not considered the intramolecular 1,2-shift of an ethylene bridge cation, which is assumed in the way of the skeletal rearrangement on treatment of triple-layered paracyclophane with Friedel-Crafts acids. A plausible mechanism is the exchange of two ethylene bridges, which may proceed through a benzvalene intermediate 41 from the first-formed product 39 . This assumption is supported by the facts that a prolonged irradiation of 38 results in increased yield of 40 with a decreased yield of normal product $\underline{39}$, and that irradiation of $\underline{39}$ in degassed cyclohexane produces the isomer 40 .

Similar photoinduced rearrangements are observed on irradiating dithia quadruple-layered metaparacyclophanes, 41 and 44 , both of which have the

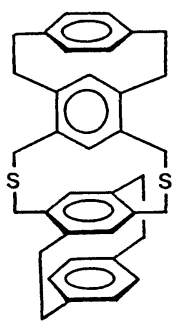

41

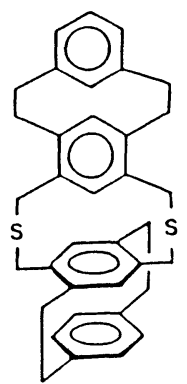

44

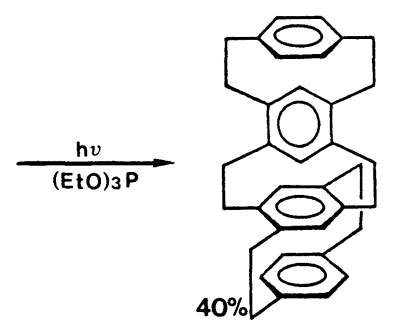

42

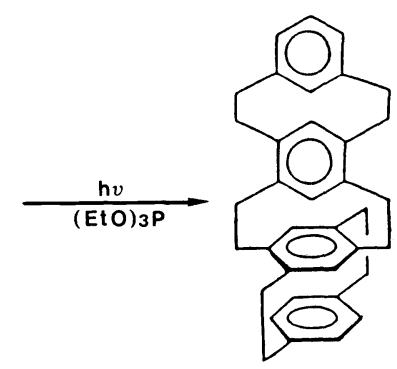

45

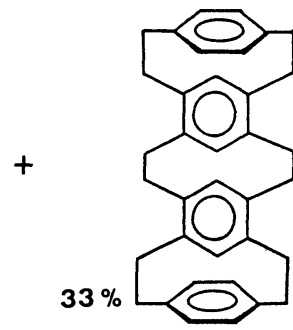

43

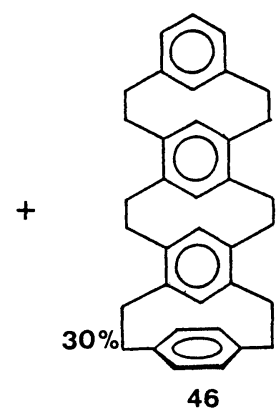


framework of $\underline{38}$ as a common molecular moiety, to give photorearranged quadruple-layered metaparacyclophanes, $\underline{43}$ and 46 , respective1y, in relative good yield (ref. 23). Such a benzvalenemechanism was also proposed for the formation of unexpected triple-layered metaparacyclophane 49 via intermediate 48 on irradiation of dithia triple-layered metacyclophane $\underline{47}$ (ref. 24).

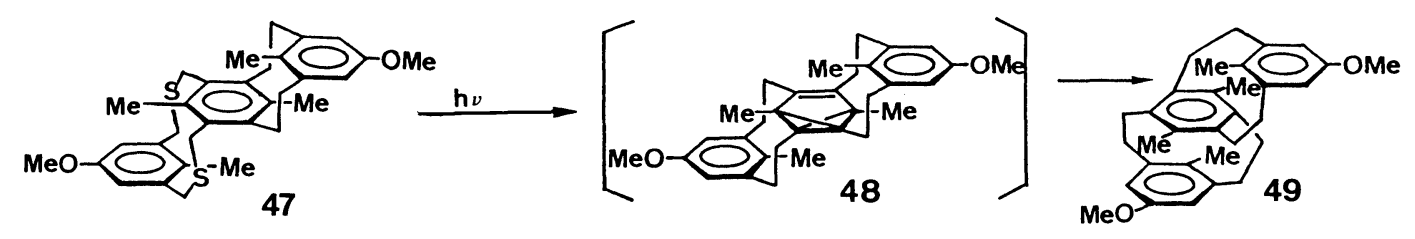

Compared with the ready photodimerization of condensed aromatics, benzene is so stable on photoinduced reaction that it has often been used as a reaction medium. Even in highly strained [2.2] paracyclophane, the two benzene rings are inert to irradiation. As described before, a few multilayered metaparacyclophanes including the [2.2] paracyclophane framework shows the photochemical exchange of two ethylene bridges to release the strain of the twisted inner benzene ring.

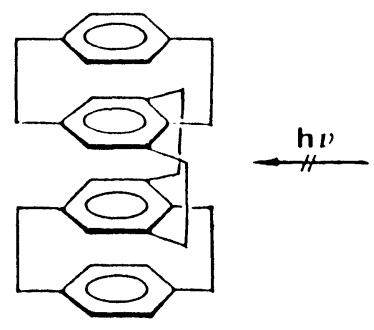

51

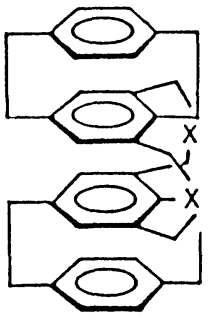

50

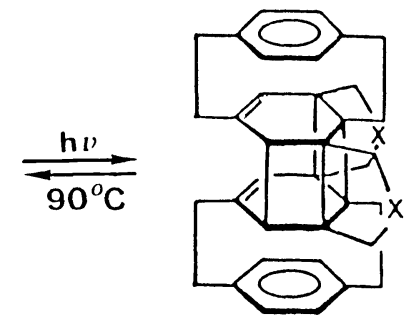

52

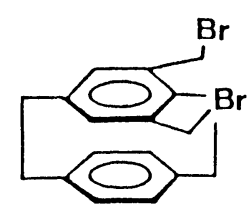

53
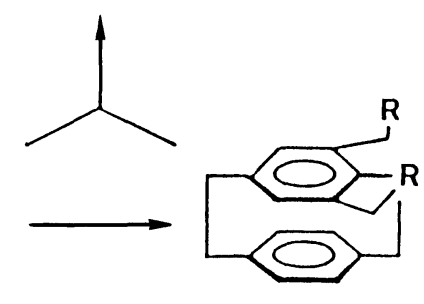

54

On the other hand, a novel photochemical reaction of benzene rings was observed in the course of a study on the synthesis of new type of quadruplelayered cyclophane $\underline{51}$ by photoinduced desulfurization of dithiacyclophane $\underline{50 b}$ (ref. 25). Dihetera quadruple-1ayered cyclophanes 50a-c are synthesized together with nearly same amounts of their anti-conformers by coupling of a key intermediate 4,8-bis(bromomethy1)[2.2] paracyclophane 53 with the corresponding chalcogenatom-substituted [2.2] paracyclophanes 54a-c (see Table 2)(ref. $26,27)$. Irradiating $\underline{50 b}$ and $\underline{50 c}$ in triethyl phosphite for extrusion of chalcogenatoms, unexpected cage compounds $\underline{52 b}$ and $\underline{52 c}$, respectively, are produced as colorless fine crystals. The structures of these photoisomers are clearly confirmed by MS, NMR, and UV spectra, that is, disappearance of inner benzene rings and, instead, formation of olefins. The possibility of another structure containing two benzvalene rings is eliminated on the basis of PMR data. Similarly cage compound 52 a is obtained in good yield by irradiation of $\underline{50 a}$. The decreased yield of $\underline{52 c}$, as shown in Table 2 , is partly ascribed to a competitive photoinduced C-Se bond fission to give a byproduct, 4,8 -dimethyl[2.2] paracyclophane in $15 \%$ yield.

After various examinations on thermal properties of the cage compounds $\underline{52 a-c}$, the thermal ringopening reaction of $\underline{52}$ in THF solution is optimized to give the original quadruple-layered cyclophanes $\underline{50 a-c}$ as shown in Table 3 . The table shows that the reaction proceeds with a relative rate of $\mathrm{Se}>\mathrm{S}>0-$ compounds. 
Table 2. Yie1ds of $\underline{50}, \underline{54}$, and photoisomerization of $\underline{50}$.

\begin{tabular}{|c|c|c|c|c|c|c|}
\hline & $\begin{array}{c}\text { y ie } 1 \mathrm{~d}(\%) \\
\underline{53} \rightarrow 54\end{array}$ & $\underline{53}+\underline{5}$ & -50 & anti & \multicolumn{2}{|c|}{$\begin{array}{c}\text { yield (\%) } \\
50 \longrightarrow 52\end{array}$} \\
\hline a & & 0 & 24 & 28 & 0 & 80 \\
\hline b & SH 81 & S & 33 & 2 & S & 83 \\
\hline c & SeCN 60 & $\mathrm{Se}$ & 27 & 36 & $\mathrm{Se}$ & 47 \\
\hline
\end{tabular}

Table 3. Thermal isomerization of $\underline{52}$ to $\underline{50}$.

\begin{tabular}{|cl|c|c|}
\hline & $\mathrm{X}$ & $T \frac{1}{2}\left(\mathrm{t}{ }^{\circ} \mathrm{C}\right)$ & yie1d $(\%)$ \\
\hline$\underline{52} \mathrm{a}$ & 0 & $2 \operatorname{hr}(90)$ & quant. \\
$\mathrm{b}$ & $\mathrm{S}$ & $30 \min (90)$ & quant. \\
$\mathrm{c}$ & $\mathrm{Se}$ & $25 \min (90)$ & 70 \\
\hline
\end{tabular}

In order to search the driving forces for these unusual photodimerization of benzene nuclei in diheteracyclophanes $\underline{50}$, photochemical behavior of a series of model compounds was studied with respect to four factors: 1) magnitude of molecular strain, 2) effect of the two outer benzene rings in 50, 3) positions of four bridges at the inner benzenes, and 4) interfacial constraint of the particular two benzene rings. On irradiation, dithiacyclophane $55(n=8)$ containing [8]paracyclophane, in which the benzene ring is wel1-known by bending comparable to that of [2.2]paracyclophane, gives a photoisomer $\underline{56}(n=8)$ in $31 \%$ yield at $-78{ }^{\circ} \mathrm{C}$ and $17 \%$ at room temperature. On the other hand, reverse thermal reaction of $\underline{56}(n=8)$ is not observed under various conditions. No photoisomer is given in the case of $\underline{55}(n=10)$.

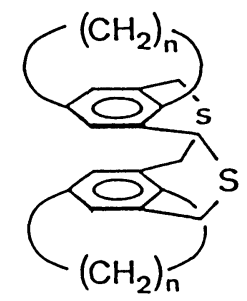

$55 n$
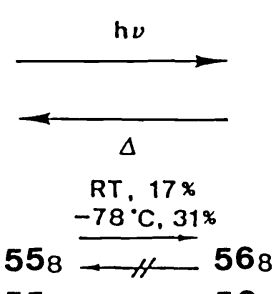

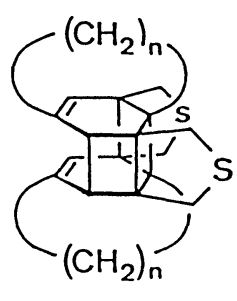

$56 n$

From photochemical examinations with various model compounds, it is concluded that the most important factor on the photodimerization is some extent of severe strain,but not too much, in the benzene ring. The outer benzene rings of photoisomers $\underline{52}$ are required for increased thermal stability of the inside cage framework but not necessarily for photodimerization. In other words, the two outer benzenes are essential to effective photochromism between 50 to $\underline{52}$.

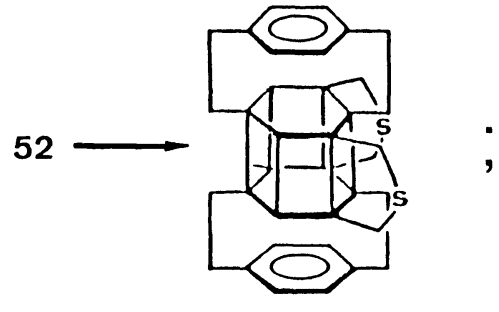

57

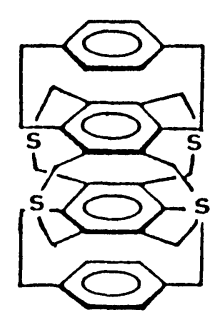

58

An attractive theme is to synthesize a hexaprismane derivative $\underline{57}$ from $\underline{52}$. A $[2+2]$ photocycloaddition of the remaining two double bonds was attempted by irradiation under many conditions. Unfortunately, the attempt resulted in the formation of small amounts of 4,8-dimethyl[2.2]paracyclophane in place of the desired hexaprismane derivative. The reasons that the reaction does not proceed are due to 1) unexpectedly long distance between the two double bonds,

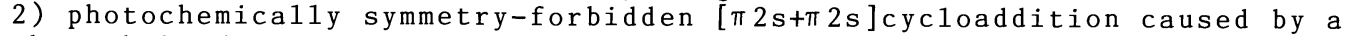
through-bond interaction of the double bond and $\sigma$-bond of adjacent cyclobutane (ref. 28), and 3) severe strain in hexaprismane framework. An attempt to synthesize a hexabridged tetrathiacyclophane $\underline{58}$ is now in progress.

\section{Acknowledgement}

The author is greatly indebted to Profs. M. Ōki and M. Kobayashi for publication. The author also wish to thank his many coworkers for participating in this project. 


\section{REFERENCES}

1. H. Hopf, J. Kleinschroth, and A. E. Mourad, Angew. Chem., 92, 388 (1980).

2. V. Boekelheide and Y. Sekine, J.Am. Chem. Soc., 103, 1777(1981).

3. a) J.A. Reiss, "Condensed Benzenoid Cyclophanes", 443-484, in "Cyclophanes II", ed. by P. M. Keehn and S. M. Rosenfeld, Academic Press, New York, 1983.

b) S. Misumi, Mem. Inst. Sci.\& Ind. Res., Osaka Univ., 36, 37 (1979).

4. S. Misumi and T. Kaneda, "Proximity Interactions of Acetylenes", 713-737, in "The Chemistry of the Carbon-Carbon Triple Bond. Part 2" ed. by

S. Patai, Wiley, New York, 1978.

5. a) S. Misumi and T. Otsubo, Acc. Chem. Res., 11, 251 (1978).

b) S. Misumi, "Multilayered Cyclophanes", 573-628, in "Cyclophanes II", ed. by P. M. Keehn and S. M. Rosenfeld, Academic Press, New York, 1983.

6. A. Iwama, T. Toyoda, M. Yoshida, T. Otsubo, Y. Sakata, and S. Misumi, Bu11. Chem. Soc. Jpn., 51, 2988 (1978).

7. T. Toyoda, A. Iwama, T. Otsubo, and S. Misumi, Bu11. Chem. Soc. Jpn., 49, $3300(1976)$.

8. Y. Koizumi, T. Toyoda, K. Miki, N. Kasai, and S. Misumi, Bul1. Chem. Soc. Jpn., 59, 239 (1986).

9. H. Mizuno, K. Nishiguchi, T. Otsubo, S. Misumi, and N. Morimoto, Acta Cryst., B33, 329 (1977).

10. Y. Fukazawa, M. Kikuchi, 0. Kajita, and S. Itô, Tetrahedron Lett., 25, 1505 (1984).

11. T. Shinmyozu, T. Inazu, and T. Yoshino, Chem. Lett., 405 (1978).

12. T. Kaneda and.S. Misumi, Bu11. Chem. Soc. Jpn., 50, 3310 (1977).

13. T. Kaneda, T. Ogawa, and S. Misumi, Tetrahedron Lett. 3373 (1973).

14. S. Inagaki, H. Fujimoto, and K. Fukui, J. Am. Chem. Soc., 98, 4693 (1976).

15. a) H. H. Wasserman and P. M. Keehn, J. Am. Chem. Soc., 89, 2770 (1967).

b) G. Kaupp and I. Zimmermann, Angew. Chem., $88,482(1 \overline{976})$.

16. a) J. H. Golden, J. Chem. Soc., $\frac{\text {, } 3741(1961)}{\text {. }}$

b) G. Kaupp, Liebigs Ann. Chem., 844 (1973).

17. T. Toyoda, N. Kasai, And S. Misumi, Bu11. Chem. Soc. Jpn., 58, 2348 (1985).

18. I. Yamashita, M. Fujii, T. Kaneda, and S. Misumi, Tetrahedron Lett., 21 , 541 (1980).

19. T. Inoue, T. Kaneda, and S. Misumi, Tetrahedron Lett., 1543 (1975).

20. T. Hayashi, N. Mataga, T. Inoue, T. Kaneda, M. Irie, and S. Misumi, J. Am. Chem. Soc., 99, 523 (1977).

21. J. Bruhin and W. Jenny, Tetrahedron Lett., 1215 (1973).

22. N. Kannen, T. Otsubo, Y. Sakata, and S. Misumi, Bu11. Chem. Soc. Jpn., $49,3307(1976)$.

23. N. Kannen, T. Otsubo, and S. Misumi, Bu11. Chem. Soc. Jpn., 49, 3208(1976).

24. T. Otsubo, D. Stusche, and V. Boeke1heide, J. Org. Chem., 43, 3466 (1978).

25. H. Higuchi, K. Takatsu, Y. Sakata, S. Misumi, and T. Otsubo, Tetrahedron Lett., 23,671 (1982).

26. H. Higuchi, M. Kugimiya, T. Otsubo, Y. Sakata, and S. Misumi, Tetrahedron Lett., 24, 2593 (1983).

27. H. Higuchi, E. Kobayashi, Y. Sakata, and S. Misumi, Tetrahedron, 42, 1731 $(1986)$.

28. a) W. Schmidt and B. T. Wilkins, Tetrahedron, 28, 5649 (1972).

b) J. Spanget-Larsen, R. Gleiter, G.Klein, C. W. Doecke, and L. A. Paquette, Chem. Ber., 113, 2120 (1980). 